\title{
Seasonal Rainfall Forecasts for the Yangtze River Basin in Summer 2019 from an Improved Climate Service
}

Philip E. BETT ${ }^{1 *}$, Nicola MARTIN ${ }^{1,2}$, Adam A. SCAIFE ${ }^{1,3}$, Nick DUNSTONE ${ }^{1}$, Gill M. MARTIN ${ }^{1}$, Nicola GOLDING ${ }^{1}$, Joanne CAMP ${ }^{1}$, Peiqun ZHANG ${ }^{4}$, Chris HEWITT ${ }^{1,5}$, Leon HERMANSON ${ }^{1}$, Chaofan LI ${ }^{6}$, Hong-Li REN ${ }^{4}$, Ying LIU ${ }^{4,7}$, Min LIU ${ }^{8}$

1 Met Office Hadley Centre, FitzRoy Road, Exeter EX1 3PB, UK

2 Plymouth Marine Laboratory, Prospect Place, Plymouth PL1 3DH, UK

3 College of Engineering, Mathematics and Physical Sciences, University of Exeter, Exeter, Devon EX4 4QF, $U K$

4 Laboratory for Climate Studies, National Climate Center, China Meteorological Administration, Beijing 100081, China

5 University of Southern Queensland, Toowoomba, Australia

6 Center for Monsoon System Research, Institute of Atmospheric Physics, Chinese Academy of Sciences, Beijing 100029, China

7 Collaborative Innovation Center on Forecast and Evaluation of Meteorological Disasters, Nanjing University of Information Science and Technology, Nanjing, China

8 Wuhan Regional Climate Centre, Wuhan 430074, China

(Submitted March 17, 2020; Accepted Mmm dd, yyyy)

Supported by the UK-China Research \& Innovation Partnership Fund through the Met Office Climate Science for Service Partnership (CSSP) China as part of the Newton Fund.

*Corresponding author: philip.bett@metoffice.gov.uk

This preprint is (C) Crown Copyright 2020 the Met Office. It has been submitted to a journal but not yet been peer reviewed. 


\begin{abstract}
Rainfall forecasts for the summer monsoon season in the Yangtze River Basin allow decision-makers to plan for possible flooding, which can affect the lives and livelihoods of millions of people.

A trial climate service was developed in 2016, producing a prototype seasonal forecast product for use by stakeholders in the region, based on forecasting rainfall directly using a dynamical model. Here we describe an improved service, based on a simple statistical downscaling approach: using a dynamical forecast of an East Asian Summer Monsoon index, seasonal-mean rainfall for the Upper and Middle/Lower Reaches of the basin can be forecast separately, with significant skill for lead times of up to at least 3 months. The skill in the different sub-basin regions depends on the target season: Rainfall skill in the Middle/Lower Reaches is significant in May-June-July (MJJ), and there is significant skill for the Upper Reaches in June-July-August (JJA). The mean rainfall for the basin as a whole can be skillfully forecast in both seasons. The forecasts issued in 2019 gave good guidance for the enhanced rainfall in the MJJ period, and the near-average conditions in JJA. Initial feedback from users in the Yangtze River Basin suggests that the improved forecast better meets their needs and will enable more robust decision-making.
\end{abstract}

Key words: seasonal forecasting, flood forecasting, Yangtze basin rainfall, East Asian Summer Monsoon

\title{
1. Introduction
}

The Yangtze River Basin has been subject to regular, heavy flooding throughout history (e.g. Plate, 2002; Yu et al., 2009), and in modern times this can affect the lives and livelihoods of millions of people. Advance knowledge of increased flood risk can allow planning to mitigate the impacts of flooding, for example by reducing the water levels in the large hydroelectric dams, such as the Three Gorges Dam, along the Yangtze and its tributaries. The summer rainfall in the Yangtze region is dominated by the impact of the East Asian Summer Monsoon (EASM). Being able to forecast summer Yangtze rainfall, and the EASM itself, at long lead times has been an important research subject for many decades (Wang et al., 2015, and references therein).

Skillful seasonal forecasts of rainfall can be produced directly from a dynamical model (e.g. Li et al., 2016), or by using statistical modelling to exploit relationships between rainfall and larger-scale climate phenomena. Those statistical predictors could themselves be produced by dynamical seasonal forecasting systems (a hybrid approach), or they could be based on recent observations. For example, El Niño conditions measured in winter sea surface temperatures are linked to greater Yangtze rainfall in the following summer (e.g. Zhang et al., 2016). Similarly, Zeng et al. (2019) demonstrated that sea surface salinity observed in the spring can be used as a predictor of summer precipitation in the middle/lower Yangtze River valley. While statistical modelling can often outperform direct dynamical modelling, it has been recognised that combining statistical modelling with dynamical model output is likely to be the optimal approach, and it naturally provides an opportunity for downscaling to the areas of most interest (e.g. Ke et al., 2011; Liu and Fan, 2012; Li and Lin, 2015; Qian et al., 2019). 
In 2015, Golding et al. (2017a) identified a clear user requirement for improved seasonal rainfall forecasts in the Yangtze River Basin (YRB) region. At the same time, Li et al. (2016) demonstrated significant forecast skill for YRB rainfall, using the Met Office GloSea5 seasonal forecasting system. A trial climate service was subsequently developed, to deliver prototype seasonal forecasts of YRB average summer rainfall to the China Meteorological Administration (CMA). The first year in which the forecasts were produced followed the large El Niño event in winter 2015-2016. The experience of previous post-El Niño heavy flooding in 1998 (Zong and Chen, 2000; Ye and Glantz, 2005) led to an expectation of enhanced rainfall for summer 2016. The dynamical seasonal forecasts showed a high probability of above-average rainfall in May-June-July (MJJ), and near-normal rainfall in June-July-August (JJA). These forecasts were borne out by observations (Yuan et al., 2017; Bett et al., 2018).

The same forecast system was run again in 2017 and 2018, incorporating updates to the GloSea5 system itself to use a larger ensemble and a longer hindcast period. In these cases however, without a strong forecast driver like El Niño, the forecasts had roughly equal probabilities for above and below-average conditions in the summer. The rainfall in the YRB in 2017 was near normal, although there was severe flooding in southern China (Wang, 2018; Zhang et al., 2018). In 2018, an easterly/north-easterly anomalous flow pattern resulted in particularly low rainfall in the region (Zhu et al., 2019), resulting in drought conditions in many areas (Zou et al., 2020).

Golding et al. (2017b) conducted further research on the use of seasonal forecasts for the YRB, including this trial climate service. Two key conclusions (Golding et al., 2019) were a desire for improved spatial resolution and longer lead times. Concurrently, the work of Liu et al. (2018) on the skill of forecasting the East Asian Summer Monsoon suggested a route for simple statistical downscaling that could help satisfy those user requirements. Following development and testing in 2018, forecasts using the enhanced prototype system were produced and issued from early 2019 for the subsequent MJJ and JJA seasons.

Here we report on those changes to our YRB forecasting system, and describe the forecast performance in summer 2019. Section 2 describes the data sets used, and Section 3 describes the methods used in our updated system. Section 4 describes the forecasts issued and compares them with the observed rainfall conditions. Section 5 summarises our results, and discusses them in the context of seasonal climate service development.

\section{Data sets}

The GloSea5 seasonal forecasting system (MacLachlan et al., 2015) uses the HadGEM3 climate model in its Global Coupled 2 configuration (GC2, Williams et al., 2015, and references therein). The climate model comprises dynamical models of the atmosphere (the Met Office Unified Model, Walters et al., 2017), the land surface (JULES, Best et al., 2011), oceans (NEMO, Madec, 2008; Megann et al., 2014) and sea ice (CICE, Hunke \& Lipscomb, 2010; Rae et al., 2015). The atmospheric model grid spacing is $0.83^{\circ}$ in longitude and $0.55^{\circ}$ in latitude, with 85 vertical levels; the ocean model uses a $0.25^{\circ}$ grid with 75 vertical levels. GloSea5 produces two initialised forecast runs per day, each extending to 210 days. In order to calibrate the forecasts, hindcasts are also produced operationally, covering a 24-year period (1993-2016), with 7 members initialised on four fixed dates each month ( $1^{\text {st }}$, $9^{\text {th }}, 17^{\text {th }}$ and $\left.25^{\text {th }}\right)$.

On any given date, a forecast ensemble can be produced by pooling together the preceding three weeks of forecast runs, making a 42-member forecast ensemble. A 
corresponding hindcast ensemble can be produced by pooling the four 7-member hindcast runs closest to each forecast member's initialisation date, and weighting them according to that lead/lag time (see MacLachlan et al., 2015 for details).

The observational precipitation data we use is the monthly $1^{\circ}$ data set from the Global Precipitation Climatology Centre (GPCC, Schneider et al., 2018a), covering a historical period to 2016. For the 2019 precipitation, we use the GPCC monthly monitoring data (Schneider et al., 2018b). For other fields, such as pressure at mean sea level (PMSL) and zonal wind, we use reanalysis data from ERA-Interim (ERAI, Dee et al., 2011) as a proxy for observational data.

\section{Forecast methodology}

Our forecast method is based on utilising the relationship between a predictor quantity from GloSea5, and an observed predictand quantity. These need not be the same physical variable, or cover the same geographical region. The forecast system described in Bett et al. (2018) used the GloSea5 model precipitation in a box covering the Yangtze River Basin $(\mathrm{YRB})$ region $\left(91-122^{\circ} \mathrm{E}, 25-35^{\circ} \mathrm{N}\right)$, to forecast the rainfall observed in the same box. In this scheme, the historical relationship between model and observations is characterised by the linear regression between the hindcast ensemble-mean rainfall and the observed rainfall, for a given season each year, and at a given lead time. A future observation is forecast by applying that linear regression relationship to the ensemble-mean forecast from GloSea5: The regression line gives the central estimate of the forecast, and the uncertainty on the linear regression, in terms of the prediction interval, quantifies the forecast uncertainty around that central estimate. This simple regression technique produces calibrated probabilistic forecasts that are bias and variance-corrected (Bett et al., 2019 describe this in more detail).

The updated forecasts for 2019 used the same principles, based on the linear regression between observed precipitation and an ensemble-mean predictor variable from the GloSea5 hindcast. Here, we use an index of the East Asian Summer Monsoon (EASM) circulation as the predictor variable. The linear regression relationship is then used with ensemble-mean forecasts of the EASM index to yield probabilistic forecasts of the future rainfall in the Yangtze basin. Because the rainfall response to the monsoon index is different in different regions, and at different periods during the monsoon season, this represents a simple form of statistical downscaling.

We use the EASM index proposed by Wang \& Fan (1999). This describes the shear vorticity in the western North Pacific, through the difference between the mean zonal wind at $850 \mathrm{hPa}\left(u_{850}\right)$ in two boxes: one centred on the East China Sea, and one centred on the South China Sea. Wang \& Fan (1999) defined the index as the southern box minus the northern box. Although this order is sometimes reversed (e.g. Wang et al., 2008), we follow Liu et al. (2018) by using the original definition. Figure 1 shows the observed circulation and rainfall responses to this EASM index: Low values correspond to anomalously anticyclonic circulation over the western North Pacific, advecting moisture further north within China, enhancing precipitation over the Yangtze River Basin. Conversely, high EASM index values correspond to anomalously cyclonic circulation in the region, leading to reduced rainfall over the Yangtze basin, but more rainfall further south in China and South East Asia. It is also clear that this EASM index is strongly related to the West Pacific Subtropical High (WPSH), with low values corresponding to a stronger (westward-extended) WPSH, and vice versa. Wang et al. (2008) showed that this EASM index captures the leading mode of variability in the EASM system: a strong Meiyu front in China, bringing enhanced rainfall to the YRB, 
associated with a suppressed western North Pacific monsoon trough, easterly vertical shear in the southern South China Sea, and an enhanced south-westerly monsoon over southern China due to the south-westward extension of the WPSH.
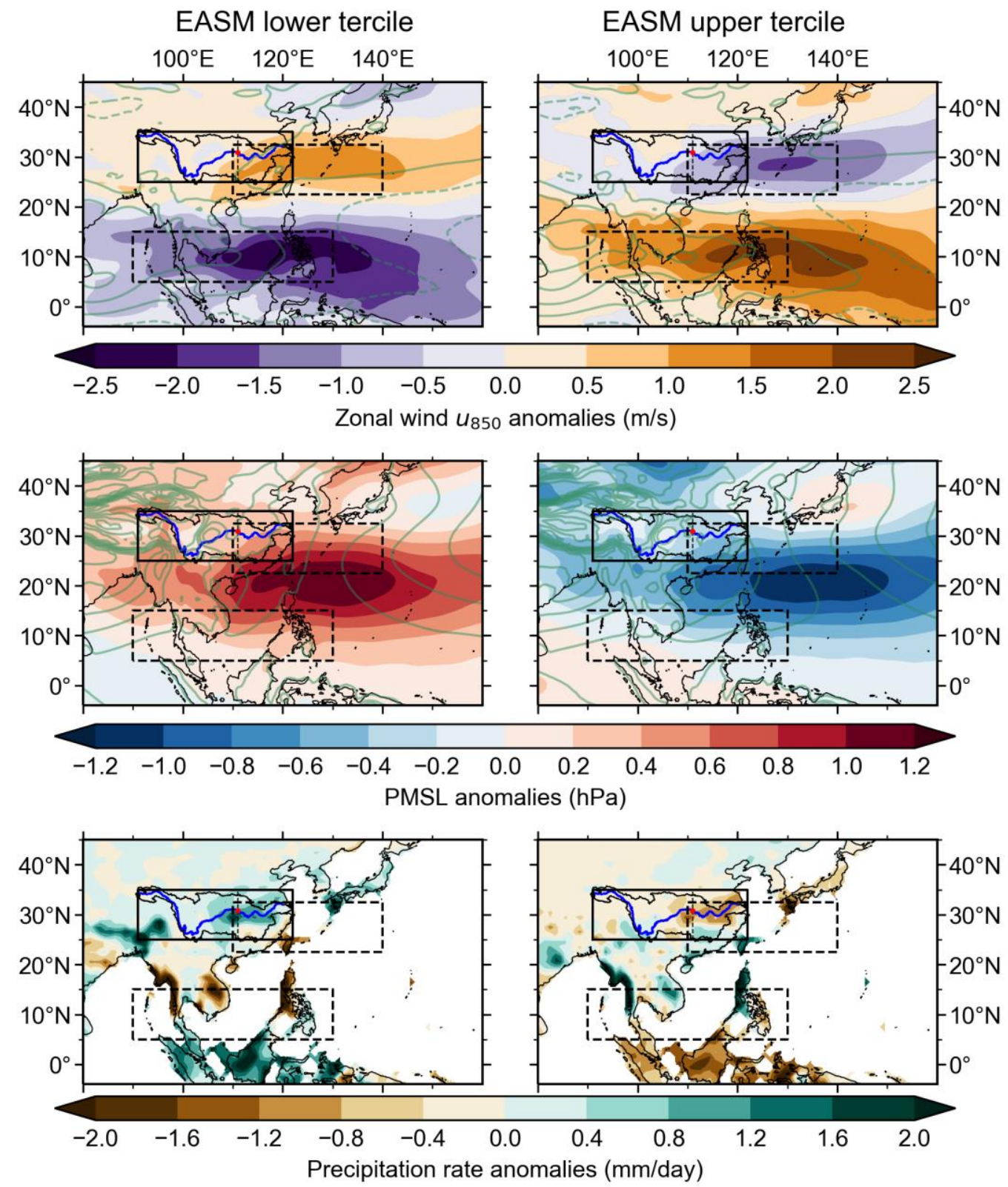

Figure 1. Composite mean responses of the seasonal mean zonal wind $u_{850}$, PMSL (from ERAI), and precipitation rate (from GPCC), for upper and lower terciles of the seasonal mean EASM index in JJA. We use the common period of the data sets here, 1979-2016. In all panels, anomalies are shown by colored shading. For the $u_{850}$ and PMSL panels, the patterns of the full-field values are indicated by green contour lines, dashed for negative values. The Yangtze River Basin and the box used in Bett et al. (2018) are drawn in black, with the Yangtze River itself in blue. The basin is subdivided at $111^{\circ} \mathrm{E}$ (thin grey dashed line) near the Three Gorges Dam (red point). The boxes used to define the EASM index are drawn with black dashed lines.

Figure 2 maps the observed anticorrelation between the EASM index and YRB precipitation, as well as the corresponding relationship when using the EASM index calculated from the GloSea5 hindcast data. This illustrates the model fidelity in reproducing the relationship between the EASM index and precipitation. Note that, as we forecast areaaverages, the spatial patterns do not need to agree in detail for our method to work. GloSea5 
also produces skillful forecasts of the EASM index itself: For the hindcast data used at a onemonth lead time, the correlation skill for the EASM in MJJ is $r=0.87$, with a $95 \%$

confidence interval from a Fisher z-transformation of 0.72-0.94; and for JJA the skill is $r=$ 0.76 , with a $95 \%$ confidence interval of $0.51-0.89$, consistent with Liu et al. (2018). This is also consistent with the high skill of this system in forecasting the WPSH (Camp et al., 2019).
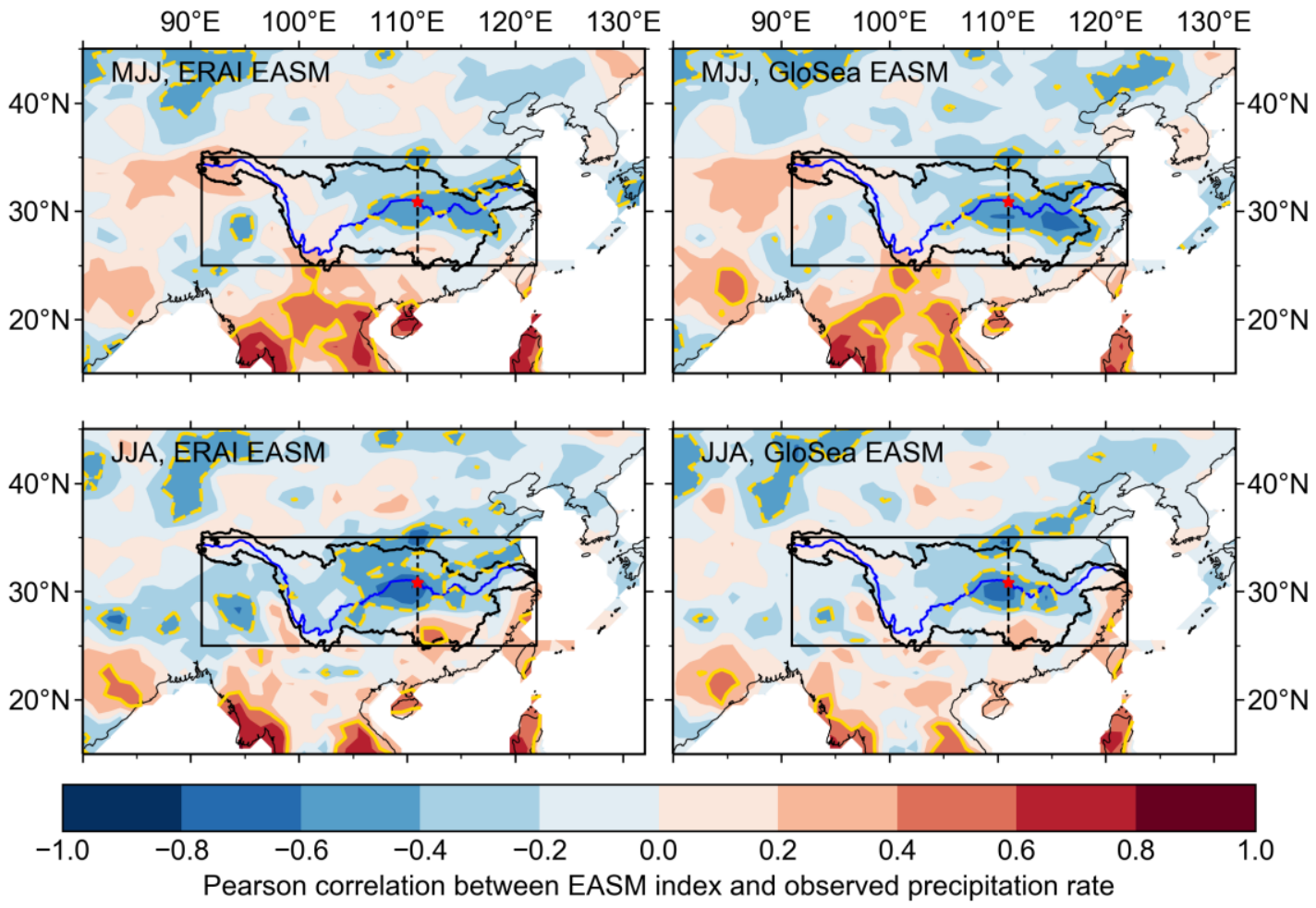

Figure 2. Correlations between EASM index and precipitation, for MJJ (top) and JJA (bottom). Observed precipitation from GPCC is used in all cases. The left-hand panels used the EASM index from ERA-Interim, and the right-hand panels use the EASM from the GloSea5 hindcast ensemblemean (right), at approximately 1 month lead time. In all panels, we use the 24 years that match the hindcast period (1993-2016). Yellow contour lines are drawn indicating significance at the 5\% level, for a Fisher $\mathrm{z}$ test on correlations of 24 points. As in Figure 1, the Yangtze River Basin and the box used in Bett et al. (2018) are drawn in black, with a basin subdivision marked at $111^{\circ} \mathrm{E}$ with a thin grey dashed line, near the Three Gorges Dam (red point). The Yangtze River is marked in blue.

An important feature of these correlation maps is the difference in spatial pattern between the early and late summer periods. The anticorrelation of the EASM index with precipitation is stronger for the western (upper) part of the basin in JJA, and stronger in the eastern (lower) part of the basin in MJJ. Wang et al. (2009) demonstrated that this westward shift of the rainfall anomalies through the summer, also seen in Wang et al. (2008), is a genuine climatological feature of the East Asian Summer Monsoon: a relatively rapid transition in rainfall patterns occurs between June and July, contrasting with smaller changes from May to June, and July to August. This is related to the seasonal advance of the WPSH, which moves northwards and eastwards over this period (Wang et al., 2009). In the earlier part of the summer, rainfall in the eastern (lower) part of the Yangtze basin is dominated by the Meiyu front. From mid-July into August however, other features of the monsoon circulation, such as typhoons and variations in the ITCZ come to dominate (Wang and LinHo, 2002; Ding and Chan, 2005). The EASM index we use here characterises the WPSH circulation that, in the early part of the season, is associated with the Meiyu rainband in particular. Martin et al. (2020) demonstrated that this index (anti-)correlates with rainfall in 
the middle/lower part of the Yangtze River basin around June. Conversely, they showed that this EASM index is unrelated to rainfall in this region in July or August.

We therefore examine the skill of the EASM index to forecast rainfall in different parts of the basin, in MJJ and JJA separately. The Yangtze River is often divided into Upper, Middle and Lower Reaches, at Yichang and Hukou respectively (e.g. Xia et al., 2016). For our purposes, we divide the basin into two regions based on this definition, using a straight line of longitude at $111^{\circ} \mathrm{E}$, in Yichang, for simplicity. This is close to the Three Gorges Dam, which is marked with a red dot on our figures. We refer to the two resulting sub-basin regions as the Upper Reaches and Middle+Lower Reaches.

Figure 3 compares the skill, in terms of the correlation magnitude $|r|$, of forecasting MJJ and JJA mean precipitation using either the hindcast EASM index or precipitation as the predictor in the linear regression. It is important to recall that these correlations are subject to relatively large sampling uncertainty: Under a Fisher $\mathrm{z}$ test, a correlation of 24 points (years) would have to be $>0.4$ to be statistically different from zero at the $5 \%$ level. Comparing the correlations against each other requires a different test, as they are not independent (they use the same set of years). Using Williams's test (Steiger, 1980) at the 5\% level, the EASMbased correlations and precipitation-based correlations shown in Figure 3 are mostly not significantly different from each other. The exceptions are for the final three JJA whole-basin forecast dates, and the penultimate forecast date for JJA Upper Reaches forecasts.

Nevertheless, it is reassuring that the results using either predictor show a consistent picture between the different seasons and regions, over the range of lead times available. Considering each region in turn: Using the EASM index in JJA provides nominally higher skill for the whole basin, at a consistently significant level, although it makes no difference for MJJ. For the Upper Reaches, the EASM index provides a way of producing significantly skilful forecasts for JJA. The precipitation-based skill in that region for JJA, and for either method in MJJ, are not statistically significant. For the Middle+Lower Reaches, equally-skilful forecasts for MJJ can be produced using either the EASM or precipitation directly. For JJA in this region, neither method results in significant skill. 

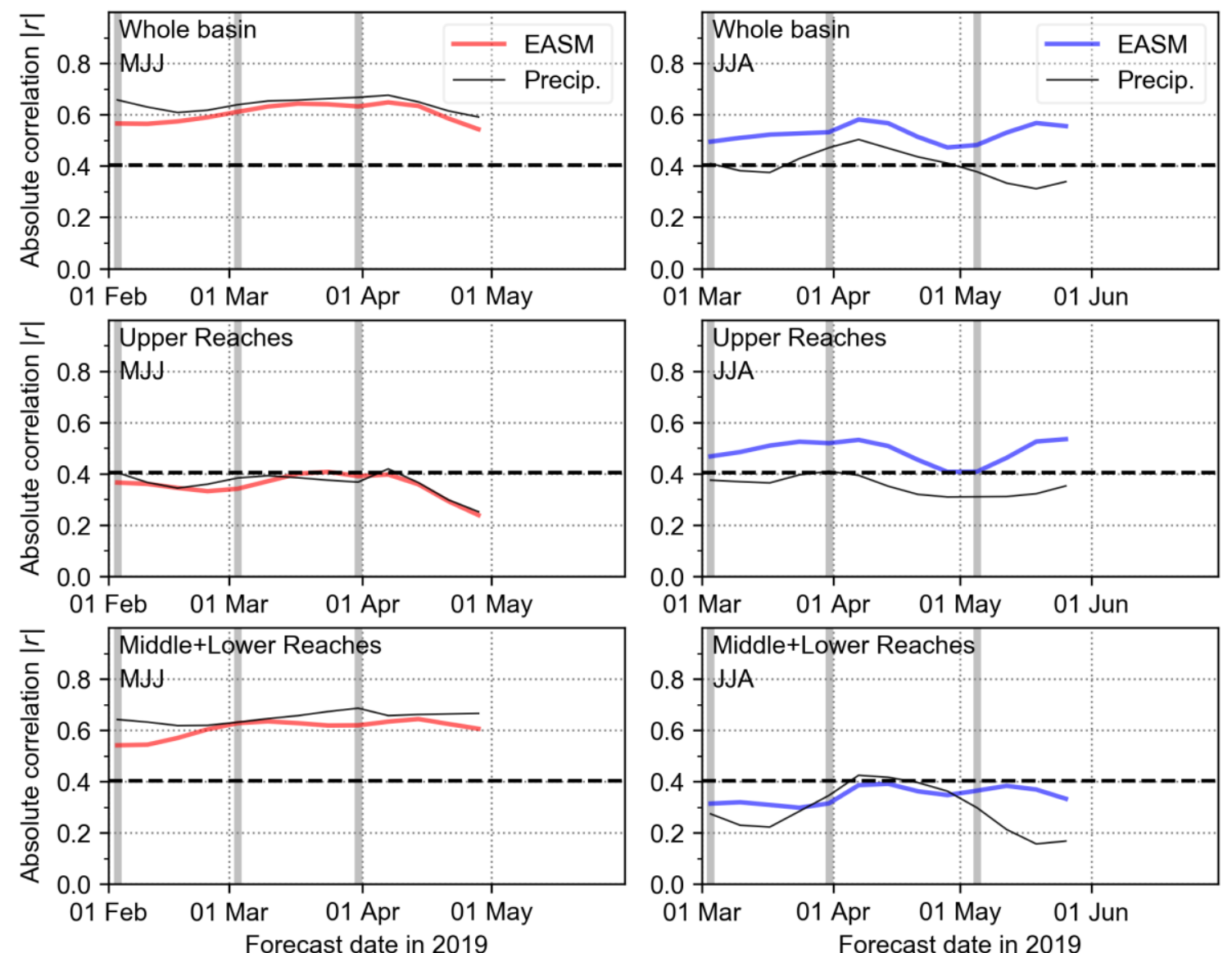

Figure 3. Time series of the absolute correlations between observed precipitation and GloSea5 EASM index (thick, coloured) and GloSea5 precipitation (thin, black), for MJJ (left) and JJA (right), in three different regions (as labelled). This shows the results from the hindcast ensembles used in our forecasts for 2019: Vertical grey bars highlight forecast release dates. The horizontal dashed line at 0.40 marks significance at the $5 \%$ level for correlations of 24 points, for a Fisher $\mathrm{z}$ test.

Having established that using the EASM index produces similar or better levels of skill than using precipitation, we implemented this change in our forecast production systems. Forecast documents were produced each week for monitoring purposes, on Sundays from February through to June. Forecasts were issued to CMA on the first Wednesday of each month, i.e. those produced on $3^{\text {rd }}$ February, $3^{\text {rd }}$ March, $31^{\text {st }}$ March, and $5^{\text {th }}$ May 2019, as marked in the figures. These dates give forecasts for MJJ and JJA at approximately 3, 2 and 1-month lead times, where available: the first release only contained information for MJJ (at a 3-month lead), and the final release only contained information for JJA (at a 1-month lead). A sample forecast document is available as supplementary material with this paper.

\section{Forecasts and Verification Results}

Figure 4 shows the forecasts for MJJ 2019 for the Middle+Lower Reaches, and Figure 5 shows the forecasts for the Upper Reaches in JJA 2019. The forecasts for the whole basin are given in the Appendix (Figures 7 and 8). In all cases, the observed mean precipitation rates are not only well within the forecast prediction intervals, but are also very close to the forecast central estimates, across all lead times. The MJJ rainfall was observed to be above average, although still easily within a standard deviation of the climatological average. The rainfall in JJA was very close to average. 

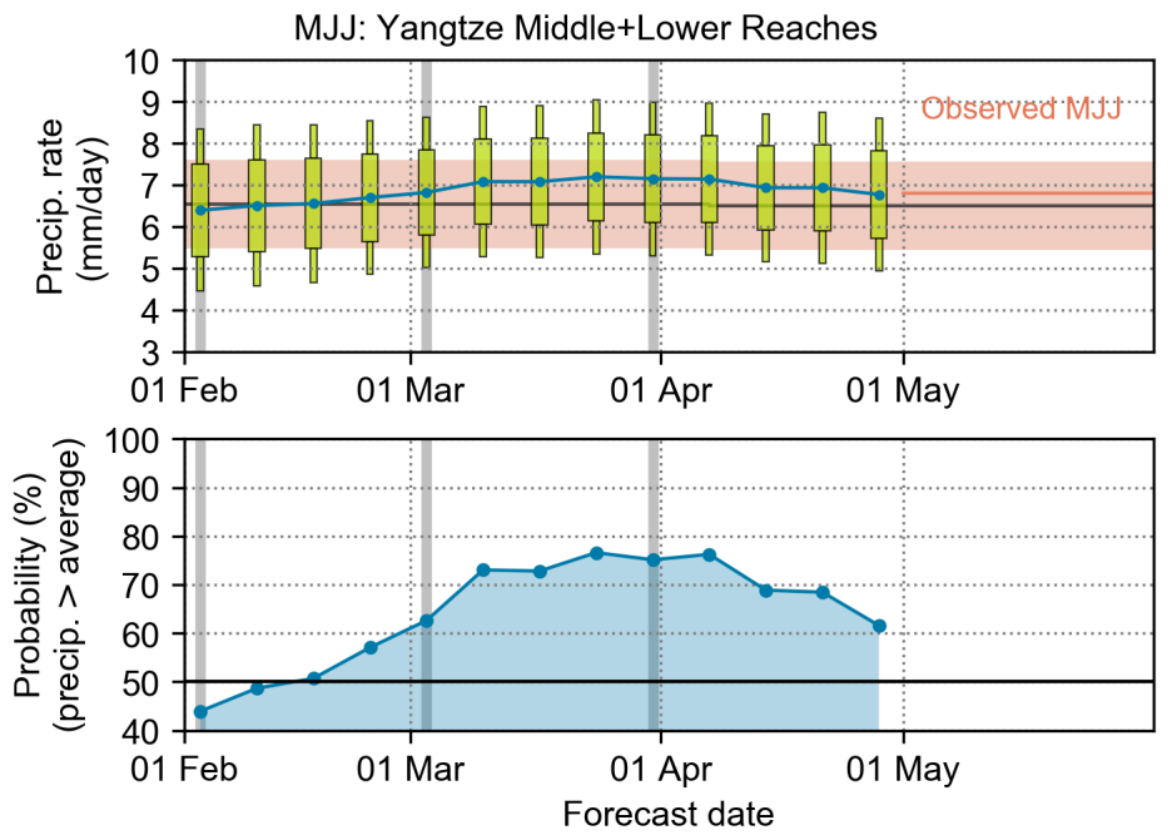

Figure 4. Forecasts for the Middle+Lower Reaches of the YRB, for MJJ 2019, as a function of lead time. Top: Forecast signal, shown as the central estimate (blue line) and the $95 \%$ and $75 \%$ prediction intervals (green boxes) from the linear regression. The observed MJJ rainfall is shown as an orange horizontal line drawn from May $1^{\text {st }}$, with the historical mean and standard deviation (over the hindcast period) shown as the solid black line and orange shading respectively. Bottom: The forecast probability of the MJJ rainfall being greater than its historical average. Forecast release dates are marked with vertical grey bars, although intermediate forecasts are produced weekly.

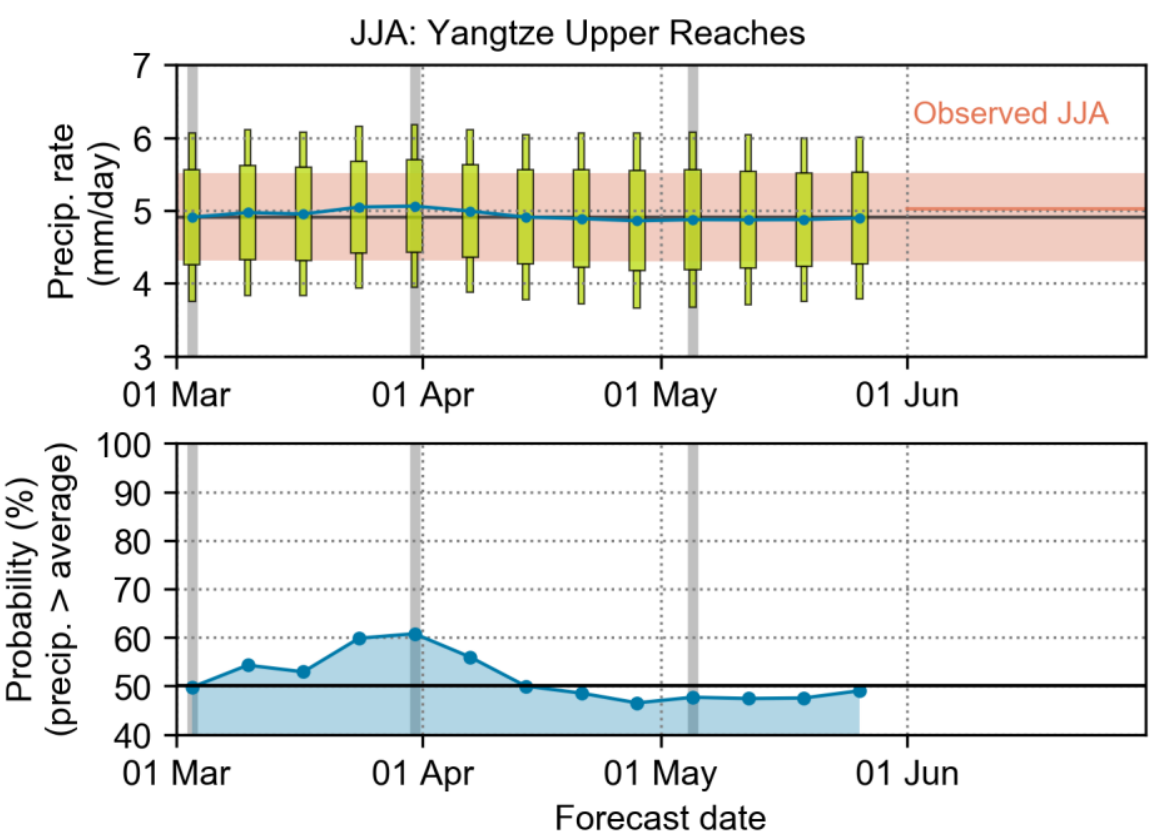

Figure 5. Forecasts as a function of lead time as in Figure 4, but here for rainfall in the Upper Reaches of the YRB, in JJA 2019.

The observed rainfall anomalies are mapped in Figure 6. This shows the mixed picture across the Yangtze River Basin in May, with heavier rainfall further south in China. June shows more widespread wet anomalies in the YRB, but the strongest signal is seen in July, particularly south of the river itself and in the Middle and Lower Reaches. The seasonal mean precipitation for MJJ reflects this, with a spatial pattern similar to that of July alone. 
The signal for JJA is similar again, but weaker: August has a strong drier-than-average anomaly across much of the basin, and dominating the Middle+Lower Reaches in particular. The area around Shanghai retains a wet anomaly in August, possibly reflecting the impact of Typhoon Lekima.

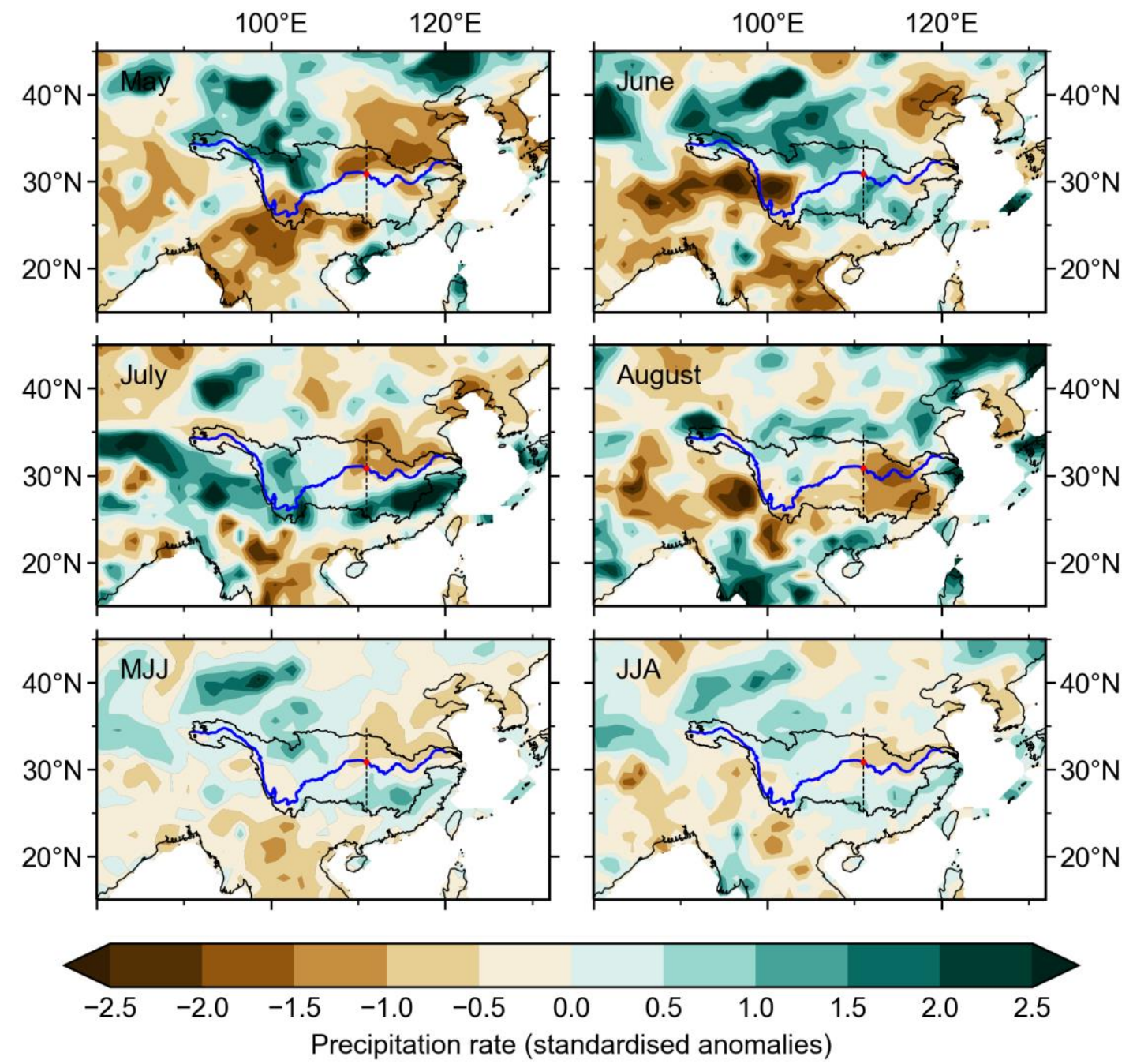

Figure 6. Observed precipitation anomalies in summer 2019. Each month and season (as labelled) is shown as the standardized anomaly with respect to their 1993-2016 mean and standard deviation. The Yangtze River basin, our subdivision at $111^{\circ} \mathrm{E}$ at the Three Gorges Dam, and the Yangtze River itself, are marked as in previous figures.

Communications with users of seasonal forecasts at the Three Gorges Dam suggest that forecasts of above average rainfall received early in the year had prompted management activities designed to release water from the dam and create space for potential flood waters. The forecasts shared from the system described in this paper gave additional confidence to these decisions, and the consistent signals seen in the forecasts as lead times reduced allowed further management adjustments to be made.

\section{Discussion and Conclusions}

At the meeting of the National People's Congress in China in March 2019, the Minister for Water Resources highlighted planned improvements in flood control, and 
pointed towards the forecasts of the China Meteorological Administration, saying "The Yangtze River is likely to suffer heavy flooding this year" (Xinhua, 2019).

The forecasts described in the previous section provided good advice for the seasonalmean, regional-mean rainfall levels within the Yangtze River Basin region, in MJJ and JJA 2019. The forecast signals were consistent for lead times of up to nearly 3 months before the start of each season. Many of the improvements made since the original version presented in Bett et al. (2018) were in direct response to clear user requirements, as described in Golding et al. (2019). Whilst a detailed evaluation of the forecast use and value in 2019 has not yet been possible, current indications agree with previous evaluations, suggesting that these updates allow for more robust and more targeted decision-making. In particular, our previous forecasts were unable to distinguish between rainfall in the upper and lower Yangtze Basin, and therefore decision-makers received no information on relative flooding risk above and below the Three Gorges Dam. This information is particularly important for the management decisions that can be made ahead of time, and so this change represents a significant improvement in that regard. In addition, the validation of the 2019 forecasts provides further evidence to users of the capability of the service, and thereby provides increased confidence for decision-making. Ongoing interaction with users throughout the process of forecast development, and the demonstrated effective and willing collaboration between scientists and decision-makers adds further value to this climate service (Golding et al., 2017b, Hewitt et al., 2020).

It is important to note that not all the user requirements identified by Golding et al. (2019) can necessarily be satisfied. Requests such as these must always be considered in the context of advances in the underpinning research and model prediction skill (e.g. Liu et al, 2018; Martin et al., 2020), so that potential improvements can be identified. This process, of trying to find ways of improving forecasts for users, can also lead to the development of other trial climate services. For example, Camp et al. (2019) demonstrated that tropical cyclone landfall can be skilfully forecast based on the WPSH, in a similar way to the use of the EASM described here (indeed, a WPSH index could be another choice of predictor for our YRB forecasts). This has been developed into a trial typhoon landfall forecast for East Asia for JJA 2019 (Camp et al., 2020). Similarly, Martin et al. (2020) demonstrated skill in forecasting rainfall in the Middle/Lower Yangtze River Basin for June alone. Preliminary examination of the test forecasts suggests that rainfall in June 2019 was correctly predicted to be slightly greater than normal, consistently at lead times from February to April.

These improved or novel services stem from discoveries of skill in existing models, together with increased understanding of the phenomena involved through on-going research around the world. They are also enhanced by improved post-processing techniques that allow that skill to be exploited efficiently without adding more noise (Bett et al., 2019). It is unlikely that large improvements in the immediate future will come directly from improved climate modelling. For example, moderate increases in model resolution (e.g., doubling) are unlikely to provide a step-change in skill (Scaife et al., 2019).

Therefore, focusing on greater understanding of underlying physical processes, and how they are reproduced in climate models, together with exploitation of post-processing techniques developed in consideration of user needs, can result in improved climate services - leading to more effective decision-making.

Acknowledgments. The Yangtze river basin shapefile used in the maps was obtained from http://worldmap.harvard.edu/data/geonode:ch_wtrshed_30mar11 and is based on the watersheds shown in the China Environmental Atlas (2000), (c) Chinese Academy of Science, Environmental Data Center. 


\section{References}

Best, M. J., M. Pryor, D. B. Clark, G. G. Rooney, Essery, C. B. Ménard, J. M. Edwards, M. A. Hendry, A. Porson, N. Gedney, L. M. Mercado, S. Sitch, E. Blyth, O. Boucher, P. M. Cox, C. S. B. Grimmond, and R. J. Harding, 2011: The Joint UK Land Environment Simulator (JULES), model description - Part 1: Energy and water fluxes. Geosci. Model Dev., 4, 677-699, doi: 10.5194/gmd-4-677-2011.

Bett, P. E., A. A. Scaife, C. Li, C. Hewitt, N. Golding, P. Zhang, N. Dunstone, D. M. Smith, H. E. Thornton, R. Lu, H-L. Ren, 2018: Seasonal Forecasts of the Summer 2016 Yangtze River Basin Rainfall. Adv. Atmos. Sci., 35, 918-926, doi: 10.1007/s00376-0187210-y.

Bett, P. E., H. E. Thornton, A. Troccoli, M. De Felice, E. Suckling, L. Dubus, Y-M. SaintDrenan, D. J. Brayshaw, 2019: A Simplified Seasonal Forecasting Strategy, Applied to Wind and Solar Power in Europe. EarthArXiv preprint, doi: 10.31223/osf.io/kzwqx.

Camp, J., M. J. Roberts, R. E. Comer, P. Wu, C. MacLachlan, P. E. Bett, N. Golding, R. Toumi, J. C. L. Chan, 2019: The western Pacific subtropical high and tropical cyclone landfall: Seasonal forecasts using the Met Office GloSea5 system. Quart. J. Roy. Meteor. Soc., 145, 105-116, doi: 10.1002/qi.3407.

Camp, J., and coauthors., 2020: Verification of the 2019 seasonal tropical cyclone landfall forecast for East Asia. J. Meteor. Res. (in review) THIS ISSUE

Dee, D. P., S. M. Uppala, A. J. Simmons, P. Berrisford, P. Poli, S. Kobayashi, U. Andrae, M. A. Balmaseda, G. Balsamo, P. Bauer, P. Bechtold, A. C. Beljaars, L. van de Berg, J. Bidlot, N. Bormann, C. Delsol, R. Dragani, M. Fuentes, A. J. Geer, L. Haimberger, S. B. Healy, H. Hersbach, E. V. Hólm, L. Isaksen, P. Kållberg, M. Köhler, M. Matricardi, A. P. McNally, B. M. Monge-Sanz, J. Morcrette, B. Park, C. Peubey, P. de Rosnay, C. Tavolato, J. Thépaut, F. Vitart, 2011: The ERA-Interim reanalysis: configuration and performance of the data assimilation system. Quart. J. Roy. Meteor. Soc., 137, 553-597, doi: $10.1002 / q j .828$.

Ding, Y., Chan, J., 2005: The East Asian summer monsoon: an overview. Meteor. Atmos. Phys. 89, 117-142, doi: 10.1007/s00703-005-0125-z.

Golding, N., C. Hewitt, P. Zhang, P. Bett, X. Fang, H. Hu, S. Nobert, 2017a: Improving user engagement and uptake of climate services in China. Climate Services, 5, 39-45, doi: 10.1016/j.cliser.2017.03.004.

Golding, N., C. Hewitt, P. Zhang, 2017b: Effective engagement for climate services: Methods in practice in China. Climate Services, 8, 72-76, doi: 10.1016/j.cliser.2017.11.002.

Golding, N., C. Hewitt, P. Zhang, M. Liu, J. Zhang, P. Bett, 2019: Co-development of a seasonal rainfall forecast service: Supporting flood risk management for the Yangtze River basin. Climate Risk Management, 23, 43-49, doi: 10.1016/j.crm.2019.01.002.

Hewitt, C., and coauthors, 2020: The Process and Benefits of Developing Prototype Climate Services - examples in China. J. Meteor. Res. (in review) THIS ISSUE

Hunke, E. C. and W. H. Lipscomb, 2010: CICE: the Los Alamos Sea Ice Model Documentation and Software Users' Manual, version 4.1. Report LA-CC-06-012, Los Alamos National Laboratory, http://oceans11.lanl.gov/trac/CICE.

Ke, Z. J., P. Q. Zhang, L. J. Chen, and L. M. Du, 2011: An experiment of a statistical downscaling forecast model for summer precipitation over China. Atmos. Oceanic. Sci. Lett., 4, 270-275, doi 10.1080/16742834.2011.11446941. 
Li, C., A. A. Scaife, R. Lu, A. Arribas, A. Brookshaw, R. E Comer, J. Li, C. MacLachlan and P. Wu, 2016: Skillful seasonal prediction of Yangtze river valley summer rainfall. Environ. Res. Lett., 11, 094002, doi: 10.1088/1748-9326/11/9/094002.

Li, F., and Z. D. Lin, 2015: Improving multi-model ensemble probabilistic prediction of Yangtze River valley summer rainfall. Adv. Atmos. Sci., 32, 497-504, doi 10.1007/s00376-014-4073-8.

Li, W., Ren HC., Zuo J. et al., 2018: Early summer southern China rainfall variability and its oceanic drivers. Climate. Dyn, 50, 4691. doi: 10.1007/s00382-017-3898-0.

Liu, Y., and K. Fan, 2012: Improve the prediction of summer precipitation in the Southeastern China by a hybrid statistical downscaling model. Meteor. Atmos. Phys., 117, 121-134, doi 10.1007/s00703-012-0201-0.

Liu, Y, H-L. Ren, A. A. Scaife, C. Li, 2018: Evaluation and statistical downscaling of East Asian summer monsoon forecasting in BCC and MOHC seasonal prediction systems. Quart. J. Roy. Meteor. Soc., 144, 2798-2811, doi: 10.1002/qj.3405.

MacLachlan, C., A. Arribas, K. A. Peterson, A. Maidens, D. Fereday, A. A. Scaife, M. Gordon, M. Vellinga, A. Williams, R. E. Comer, J. Camp, P. Xavier, and G. Madec, 2015: Global Seasonal forecast system version 5 (GloSea5): a high-resolution seasonal forecast system. Quart. J. Roy. Meteor. Soc., 141, 1072-1084, doi: 10.1002/qj.2396.

Madec, G, 2008: NEMO ocean engine. Note du Pôle de modélisation 27, Institut Pierre-Simon Laplace, http://www.nemo-ocean.eu/About-NEMO/Reference-manuals.

Martin, G. M., N. J. Dunstone, A. A. Scaife, P. E. Bett, 2020: Predicting June mean rainfall in the middle/lower Yangtze River basin. Adv. Atmos. Sci., 37, 29-41, doi: 10.1007/s00376-019-9051-8.

Megann, A., D. Storkey, Y. Aksenov, S. Alderson, D. Calvert, T. Graham, P. Hyder, J. Siddorn, and B. Sinha, 2014: GO5.0: the joint NERC-Met Office NEMO global ocean model for use in coupled and forced applications. Geosci. Model Dev., 7, 1069-1092, doi: $10.5194 /$ gmd-7-1069-2014.

Plate, E. J., 2002: Flood risk and flood management. J. Hydrol., 267, 2-11, doi 10.1016/s0022-1694(02)00135-X.

Qian, S., J. Chen, X. Li, C. Xu, S. Guo, H. Chen, and X. Wu, 2019: Seasonal rainfall forecasting for the Yangtze River basin using statistical and dynamical models. Int. J. Climatol. doi 10.1002/joc.6216.

Rae, J. G. L., H. T. Hewitt, A. B. Keen, J. K. Ridley, A. E. West, C. M. Harris, E. C. Hunke, and D. N. Walters, 2015: Development of the Global Sea Ice 6.0 CICE configuration for the Met Office Global Coupled model. Geosci. Model Dev., 8, 2221-2230, doi: 10.5194/gmd-8-2221-2015.

Scaife, A. A., J. Camp, R. Comer, P. Davis, N. Dunstone, M. Gordon, C. MacLachlan, N. Martin, Y. Nie, H-L. Ren, M. Roberts, W. Robinson, D. Smith, P. L. Vidale, 2019: Does increased atmospheric resolution improve seasonal climate predictions? Atmos. Sci. Lett. 20, e922, doi: 10.1002/asl.922.

Schneider, U., A. Becker, P. Finger, A. Meyer-Christoffer, M. Ziese, 2018a: GPCC Full Data Monthly Product Version 2018 at $1.0^{\circ}$ : Monthly Land-Surface Precipitation from RainGauges built on GTS-based and Historical Data. Deutscher Wetterdienst, doi: 10.5676/DWD_GPCC/FD_M_V2018_100.

Schneider, Udo, A. Becker, P. Finger, A. Meyer-Christoffer, M. Ziese, 2018b: GPCC Monitoring Product: Near Real-Time Monthly Land-Surface Precipitation from RainGauges based on SYNOP and CLIMAT data. Deutscher Wetterdienst, doi: 10.5676/DWD_GPCC/MP_M_V6_100. 
Steiger, J, 1980: Tests for comparing elements of a correlation matrix. Psychol. Bull., 87, 245-251, doi: 10.1037/0033-2909.87.2.245.

Walters, D., I. Boutle, M. Brooks, T. Melvin, R. Stratton, S. Vosper, H. Wells, K. Williams, N. Wood, T. Allen, A. Bushell, D. Copsey, P. Earnshaw, J. Edwards, M. Gross, S. Hardiman, C. Harris, J. Heming, N. Klingaman, R. Levine, J. Manners, G. Martin, S. Milton, M. Mittermaier, C. Morcrette, T. Riddick, M. Roberts, C. Sanchez, P. Selwood, A. Stirling, C. Smith, D. Suri, W. Tennant, P. L. Vidale, J. Wilkinson, M. Willett, S. Woolnough, and P. Xavier, 2017: The Met Office Unified Model Global Atmosphere 6.0/6.1 and JULES Global Land 6.0/6.1 configurations. Geosci. Model Dev., 10, 14871520, doi: 10.5194/gmd-10-1487-2017.

Wang, B. and Z. Fan, 1999: Choice of South Asian Summer Monsoon Indices. Bull. Amer.

Meteor. Soc., 80, 629-638, doi: 10.1175/1520-

0477(1999)080<0629:COSASM>2.0.CO;2.

Wang, B. and LinHo, 2002: Rainy season of the Asian-Pacific summer monsoon. J. Climate, 15, 386-398, doi: 10.1175/1520-0442(2002)015<0386:RSOTAP>2.0.CO;2.

Wang, B. and S-I. An, 2005: A method for detecting season-dependent modes of climate variability: S-EOF analysis. Geophys. Res. Lett., 32, L15710, doi: 10.1029/2005GL022709.

Wang, B., Wu Z., Li J., Liu J., Chang C.-P., Ding Y. and Wu G., 2008: How to measure the strength of the East Asian summer monsoon. J. Climate, 21, 4449-4463, doi: 10.1175/2008JCLI2183.1.

Wang, B., J. Liu, J. Yang, T. Zhou, and Z. Wu, 2009: Distinct Principal Modes of Early and Late Summer Rainfall Anomalies in East Asia. J. Climate, 22, 3864-3875, doi: 10.1175/2009JCLI2850.1.

Wang, B., 2018: Global monsoon summary [in "State of the Climate in 2017"]. Bull. Amer. Meteor. Soc., 99, S111-S112, doi: 10.1175/2018BAMSStateoftheClimate.1.

Wang, H., K. Fan, J. Sun, S. Li, Z. Lin, G. Zhou, L. Chen, X. Lang, F. Li, Y. Zhu, H. Chen, F. Zheng, 2015: A review of seasonal climate prediction research in China. Adv. Atmos. Sci., 32, 149-168, doi 10.1007/s00376-014-0016-7.

Williams, K. D., C. M. Harris, A. Bodas-Salcedo, J. Camp, R. E. Comer, D. Copsey, D. Fereday, T. Graham, R. Hill, T. Hinton, P. Hyder, S. Ineson, G. Masato, S. F. Milton, M. J. Roberts, D. P. Rowell, C. Sanchez, A. Shelly, B. Sinha, D. N. Walters, A. West, T. Woollings, and P. K. Xavier, 2015: The Met Office Global Coupled model 2.0 (GC2) configuration. Geosci. Model Dev., 8, 1509-1524, doi:10.5194/gmd-8-1509$\underline{2015}$.

Xia, J., S. Deng, J. Lu, Q. Xu, Q. Zong, G. Tan, 2016: Dynamic channel adjustments in the Jingjiang Reach of the Middle Yangtze River. Scientific Reports, 6, 22802, doi: $10.1038 /$ srep22802.

Xinhua News Agency, 2019: China to step up flood control in 2019: minister. http://www.xinhuanet.com/english/2019-03/12/c_137889023.htm (last accessed 3 March 2020).

Ye, Q., Glantz, M.H, 2005: The 1998 Yangtze Floods: The Use of Short-Term Forecasts in the Context of Seasonal to Interannual Water Resource Management. Mitig. Adapt. Strat. Glob. Change 10, 159-182, doi: 10.1007/s11027-005-7838-7.

Yu, F. L., Z. Y. Chen, X. Y. Ren, and G. F. Yang, 2009: Analysis of historical floods on the Yangtze River, China: Characteristics and explanations. Geomorphology, 113, 210216, doi: 10.1016/j.geomorph.2009.03.008. 
Yuan, Y., H. Gao, W. J. Li, Y. J. Liu, L. J. Chen, B. Zhou, and Y. H. Ding, 2017: The 2016 summer floods in China and associated physical mechanisms: A comparison with 1998. J. Meteor. Res., 31, 261-277, doi: 10.1007/s13351-017-6192-5.

Zhang, P., T. C. Lee, Y. Mochizuki, S.-E. Lee, L. Oyunjargal, B. Timbal, 2018: East and Southeast Asia [in "State of the Climate in 2017"]. Bull. Amer. Meteor. Soc., 99, S237S239, doi: 10.1175/2018BAMSStateoftheClimate.1.

Zhang, W. J., F.-F. Jin, M. F. Stuecker, A. T. Wittenberg, A. Timmermann, H.-L. Ren, J.-S. Kug, W. Cai, M. Cane, 2016: Unraveling El Niño's impact on the East Asian Monsoon and Yangtze River summer flooding. Geophys. Res. Lett., 43, 11,375-11,382, doi: $10.1002 / 2016 \mathrm{gl} 1071190$.

Zhu, Z., T. Li, A. Shimpo, 2019: The weakest East Asian Summer Monsoon during the past 40 years [in "State of the Climate in 2018"]. Bull. Amer. Meteor. Soc., 100, S238-S239, doi: 10.1175/2019BAMSStateoftheClimate.1.

Zeng, L., R. Schmitt, L. Li, Q. Wang, and D. Wang, 2019: Forecast of summer precipitation in the Yangtze River Valley based on South China Sea springtime sea surface salinity. Climate Dyn., 53 5495--5509, doi: 10.1007/s00382-019-04878-y

Zong, Y. and Chen, X, 2000: The 1998 Flood on the Yangtze, China. Nat. Hazards, 22, 165, doi: $10.1023 / \mathrm{A}: 1008119805106$.

Zou, X., X. Chen, H. Zeng, T. Cue, and Q. Zhang, 2020: State of the climate over the Three Gorges Region of the Yangtze River in 2018. Atmos. Oceanic Sci. Lett., 13, 48-54, doi: $10.1080 / 16742834.2020 .1693879$.

\section{Appendix}

Forecasts of rainfall in the Yangtze River Basin as a whole are presented here in Figure 7 (for MJJ) and Figure 8 (for JJA).
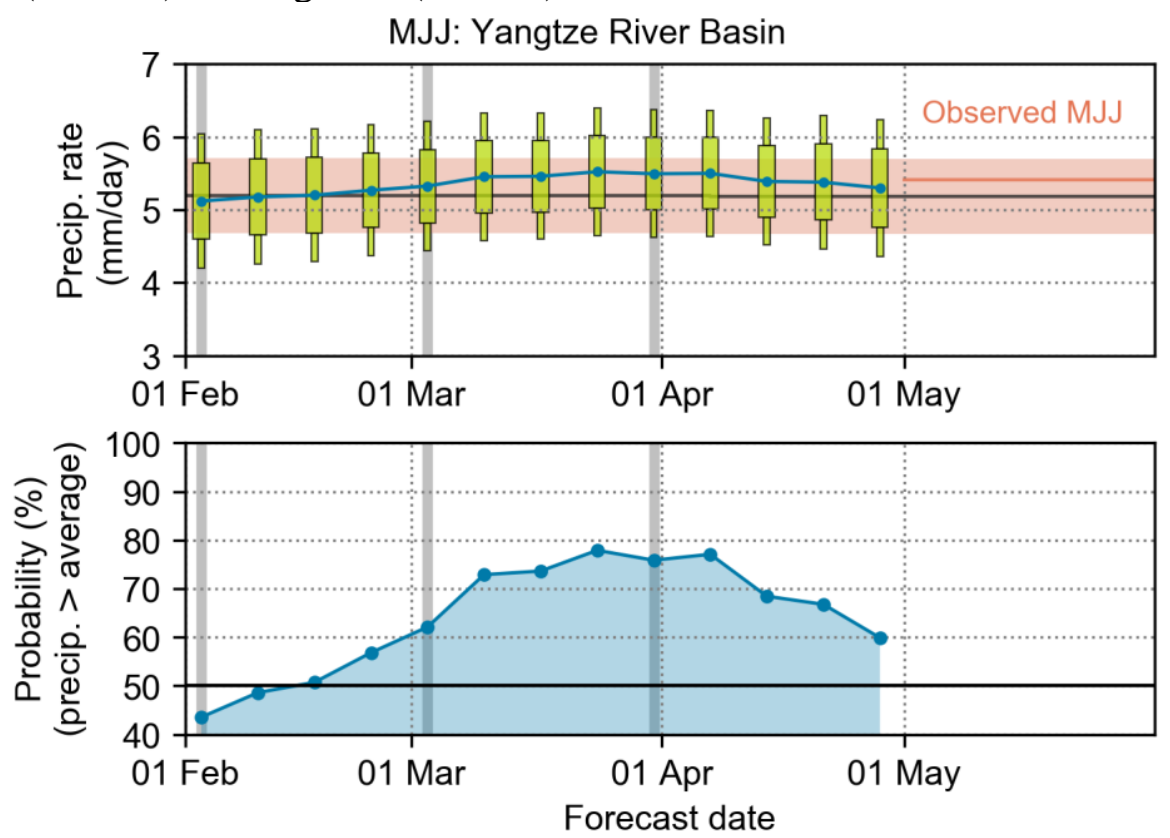

Figure 7. Forecasts for MJJ 2019 as a function of lead time, as in Figure 4, but for the whole Yangtze River Basin. 


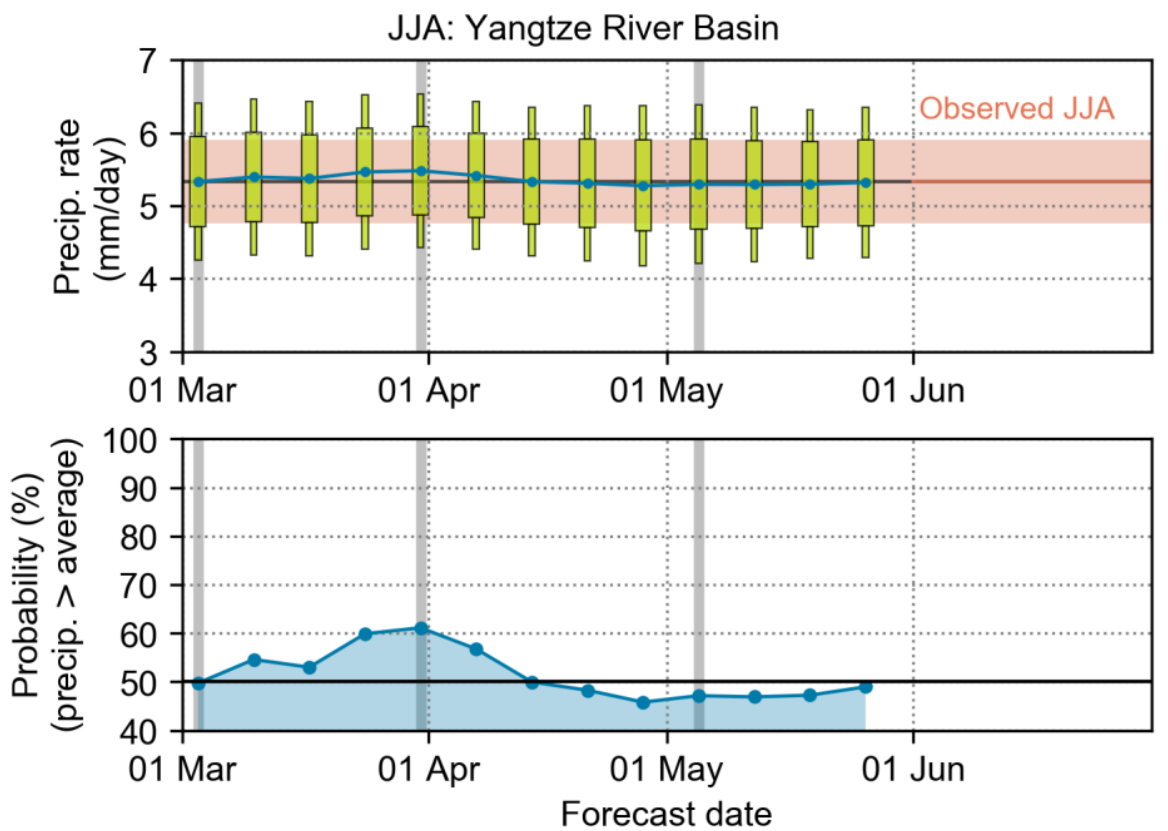

Figure 8. Forecasts for JJA 2019 as a function of lead time, as in Figure 5, but for the whole Yangtze River Basin. 